\title{
Resolution of giant basilar artery aneurysm compression and reversal of sensorineural hearing loss with use of a flow diverter: case report
}

\author{
Laila M. Mohammad, MD, ${ }^{1}$ Alexander L. Coon, MD, ${ }^{2}$ and Andrew P. Carlson, MD, MS-CR ${ }^{1}$ \\ 'Department of Neurosurgery, University of New Mexico School of Medicine, Albuquerque, New Mexico; and 2Department of \\ Neurosurgery, Johns Hopkins University, Baltimore, Maryland \\ The authors present an unusual case of a 15-year-old boy in whom sensorineural hearing loss and disequilibrium \\ developed in the setting of a giant basilar artery aneurysm. This patient was treated with a flow-diverting stent and had \\ complete resolution of his clinical symptoms including hearing loss. This case demonstrates the efficacy of flow diversion \\ in select pediatric patients with posterior circulation aneurysms. The features that are thought to result in successful \\ treatment are discussed.
}

https://thejns.org/doi/abs/10.3171/2016.9.PEDS16428

KEY WORDS giant basilar artery aneurysm; endovascular techniques; flow diversion; posterior circulation; brainstem; vascular disorders

$\mathrm{S}$ ENSORINEURAL hearing loss in patients with mass lesions, such as giant aneurysms, in the cerebellopontine angle has been reported on in the literature..$^{20}$ Open surgical treatment of these giant lesions is rarely curative and often relies on flow reversal or flow reduction to ameliorate symptoms. ${ }^{5,8,16}$ Flow diversion has represented a paradigm shift in the treatment of giant symptomatic primarily cavernous carotid artery aneurysms, although its use in the posterior circulation has resulted in mixed outcomes. ${ }^{11,15}$ Severe hearing loss resulting from compressive mass lesions is rarely reversible. The authors discuss a case that demonstrates both an angiographically curative treatment of a giant BA aneurysm and complete resolution of compressive symptoms and hearing loss after treatment with a Pipeline Embolization Device (PED; Medtronic Neurovascular).

\section{Case Report}

History and Clinical Examination

This 15-year-old boy presented to the neurosurgery clinic after a 1-year history of left-sided hearing loss and disequilibrium. An audiogram demonstrated left-sided sensorineural hearing loss (Fig. 1). On the left side, the pa- tient's hearing was essentially absent, with the inability to measure pure tone average or appreciate speech discrimination. Because of these findings, MRI of the brain was performed at an outside hospital, and images demonstrated a giant $39 \times 36-\mathrm{mm}$ partially thrombosed aneurysm in the left cerebellopontine angle, concerning for a basilar artery (BA) aneurysm (Fig. 2). Neurological examination was only significant for left-sided hearing loss and mild dysmetria.

\section{Neuroimaging Studies, Endovascular Treatment, and Outcome}

A diagnostic cerebral angiogram revealed a $27 \times 14$ $\mathrm{mm}$ irregular filling component of a much larger partially thrombosed BA aneurysm at the level of the anterior inferior cerebellar arteries (AICAs) (Fig. 3). This lesion was not thought to be a good candidate for stent coiling as the coils would likely migrate into the thrombus, requiring repeated treatments, potentially worsening the mass effect. From a surgical perspective, we considered both flow reduction with unilateral vertebral occlusion and flow reversal with bilateral vertebral occlusion and a possible superficial temporal artery-posterior cerebral artery bypass. However, since this treatment was unlikely to occlude the

ABBREVIATIONS AICA = anterior inferior cerebellar artery; BA = basilar artery; PED = Pipeline Embolization Device; VA = vertebral artery. SUBMITTED July 26, 2016. ACCEPTED September 27, 2016.

INCLUDE WHEN CITING Published online April 28, 2017; DOI: 10.3171/2016.9.PEDS16428. 
RIGHT PURE TONE AUDIOGRAM

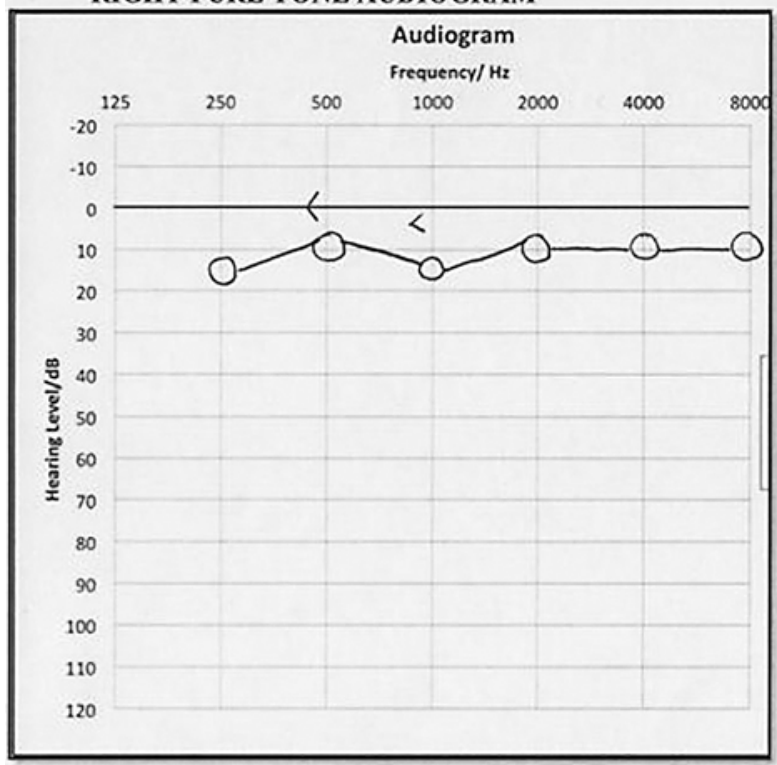

LEFT PURE TONE AUDIOGRAM

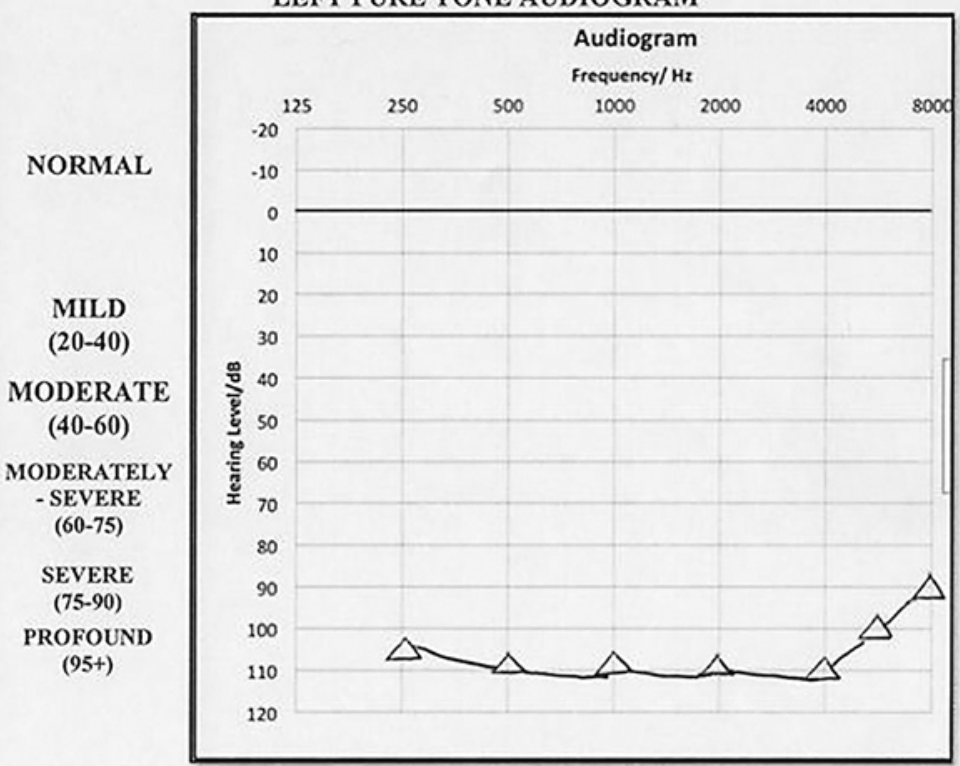

FIG. 1. Initial pure tone audiograms demonstrating normal hearing in the right ear (left) and profound hearing loss in the left ear (right).

aneurysm, a debulking procedure might also need to be considered, possibly with attempted clipping of the neck. Though flow diversion with the PED was off-label in this case, we felt that, compared with the alternative options, this treatment was reasonable to consider. After discussion with the family about these various options, we chose to proceed with embolization using the PED.

Prior to the procedure, the patient was started on as-

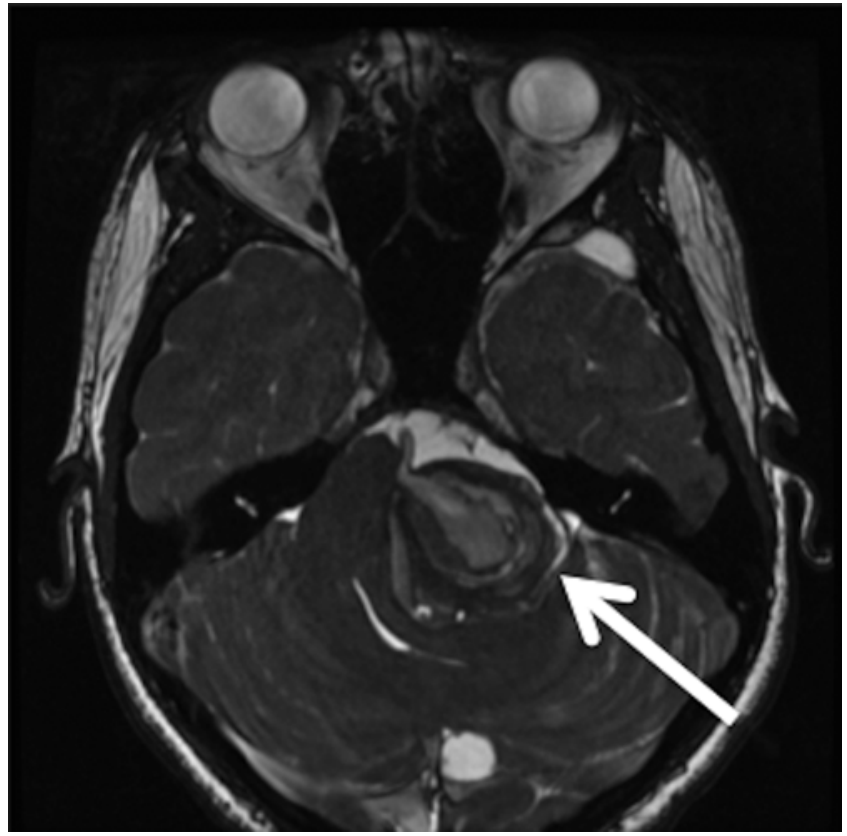

FIG. 2. Constructive interference in steady state (CISS) axial MRI sequence of the brain demonstrating a giant $39 \times 36-\mathrm{mm}$ partially thrombosed aneurysm (solid arrow) in the left cerebellopontine angle, concerning for a BA aneurysm. pirin (325 mg) and Plavix (75 mg). There was no sign of hydrocephalus, but because of the significant mass effect, the patient was placed on dexamethasone to avoid shunting, though preprocedural shunting was considered. Bilateral vertebral artery (VA) access was obtained, and the PED was placed from the distal BA to the left VA. Special care was taken to appose the device perfectly to both AICAs. This ensures that there is no space between the device and the vessel wall, which could result in thrombosis. A coiling catheter was jailed from the right VA into the aneurysm dome; and after deployment of the device, coil occlusion of the aneurysm was completed. Because of the high density of the PED, a coiling catheter cannot be placed through the device, so it has to be placed prior to deployment. The device is then deployed with the coiling catheter tip in the aneurysm and the catheter between the device and the vessel "jailed." Once coiling is complete, the catheter is removed. A follow-up angiogram showed successful deployment, good vessel apposition, and minimal filling near the base of the aneurysm (Fig. 4).

The 6-month follow-up angiogram demonstrated dramatic remodeling of the patient's giant basilar trunk aneurysm and preservation of both AICA vessels at its neck. The device also appeared to be well apposed to the left VA across the neck of the aneurysm to the mid-distal BA, with only very subtle delayed filling into the aneurysm (Fig. 5).

The repeat angiogram 9 months postembolization demonstrated no evidence of residual filling and complete separation of the lumen of the BA from the coil mass. Also observed was a smooth contour of the basilar trunk at the level of the coiled aneurysm, with no evidence of thrombosis in the bilateral AICAs or BA perforators (Fig. 6).

At 21 months postembolization the patient underwent a repeat audiogram that demonstrated essential normalization of his left-sided hearing. The follow-up audiogram demonstrated $96 \%$ speech recognition at $70 \mathrm{~dB}$ and 

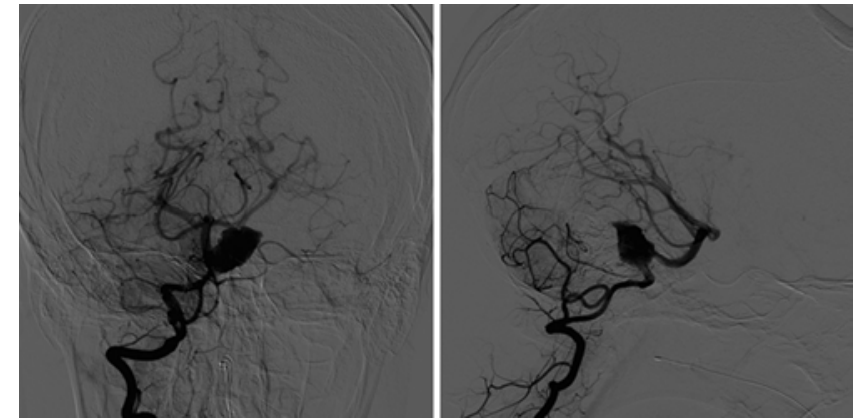

FIG. 3. Preoperative anteroposterior (left) and lateral (right) cerebral angiograms demonstrating a $27 \times 14-\mathrm{mm}$ irregular filling component of a much larger partially thrombosed BA aneurysm at the level of the AICAs.

a speech recognition threshold of $25 \mathrm{~dB}$ (Fig. 7). Repeat MRI/MR angiography performed 2 years postembolization demonstrated retraction of the aneurysm size and increased space around the brainstem and internal auditory canal bilaterally (Fig. 8).

\section{Discussion}

Flow diversion has represented a disruptive technology in the treatment of intracranial aneurysms. The principle is that a stent-like device with significantly higher density is placed across the neck of an aneurysm and redirects the jet of blood thought to be responsible for aneurysm formation and growth. The porosity of the device is balanced so that it creates stasis within the dome of the aneurysm and gradual thrombosis but, unlike a covered stent, has adequate openings so that covered branch vessels can remain patent. The only currently approved devices in the US are the PED and the second-generation Pipeline Flex (Medtronic Neurovascular). Several other devices are in trials in the US and are available internationally.

Giant vertebrobasilar aneurysms carry a high rate of morbidity, and, as of yet, no treatment modality has significantly improved on the dismal natural history of the lesion. ${ }^{4}$ The most widely accepted treatment is proximal occlusion with distal bypass or reliance on retrograde filling of the BA through the posterior communicating arteries. ${ }^{4}$ The advantage to this approach includes reducing the risk of aneurysm rupture by diminishing the influx of blood
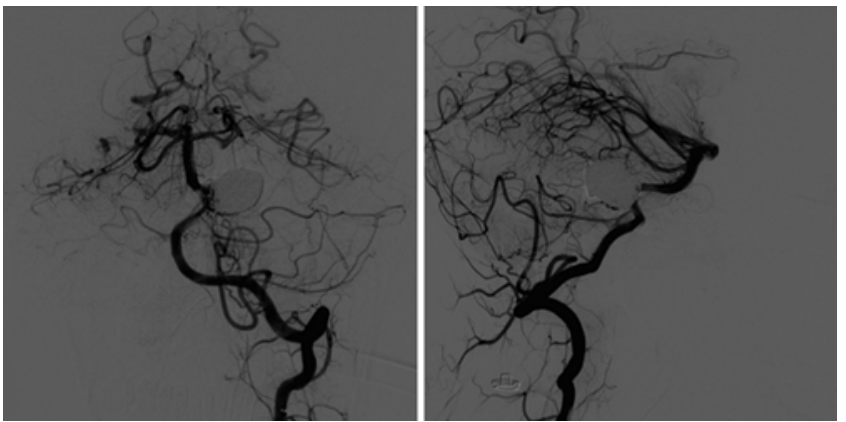

FIG. 4. Postoperative anteroposterior (left) and lateral (right) cerebral angiograms revealing successful deployment of the PED and occlusion of the BA aneurysm.

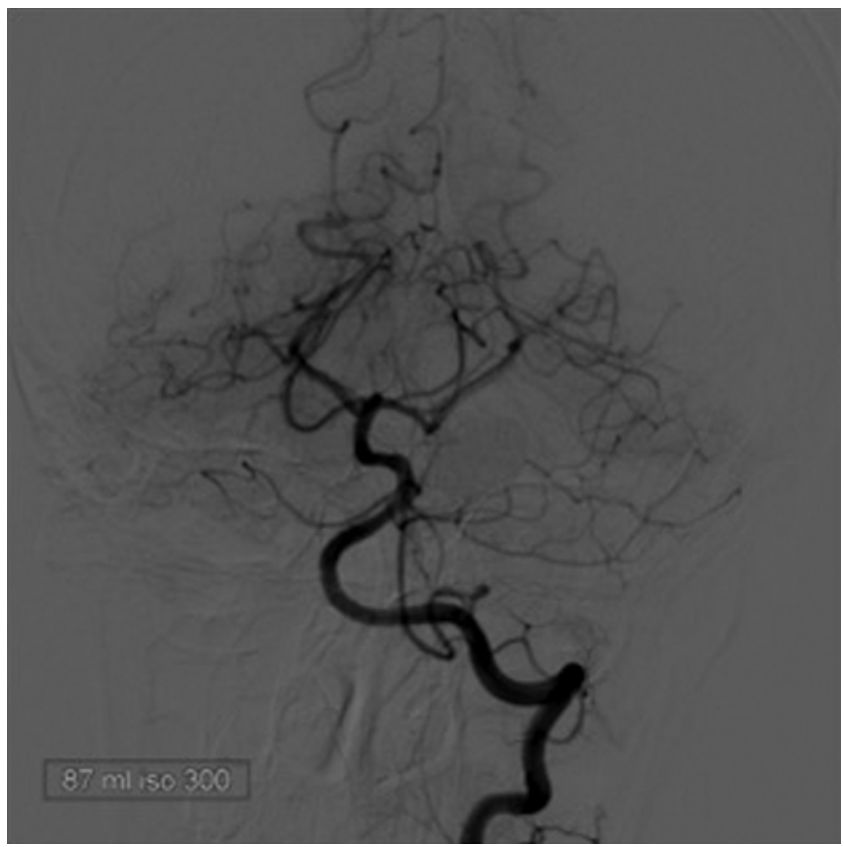

FIG. 5. Six-month postembolization anteroposterior cerebral angiogram demonstrating dramatic remodeling of the patient's giant basilar trunk aneurysm with preservation of both AICA vessels at its neck.

into the aneurysm, but it is unlikely to be curative. The Pipeline for Uncoilable or Failed Aneurysms trial demonstrated that the use of the PED was a safe and effective treatment for giant anterior circulation aneurysms, with

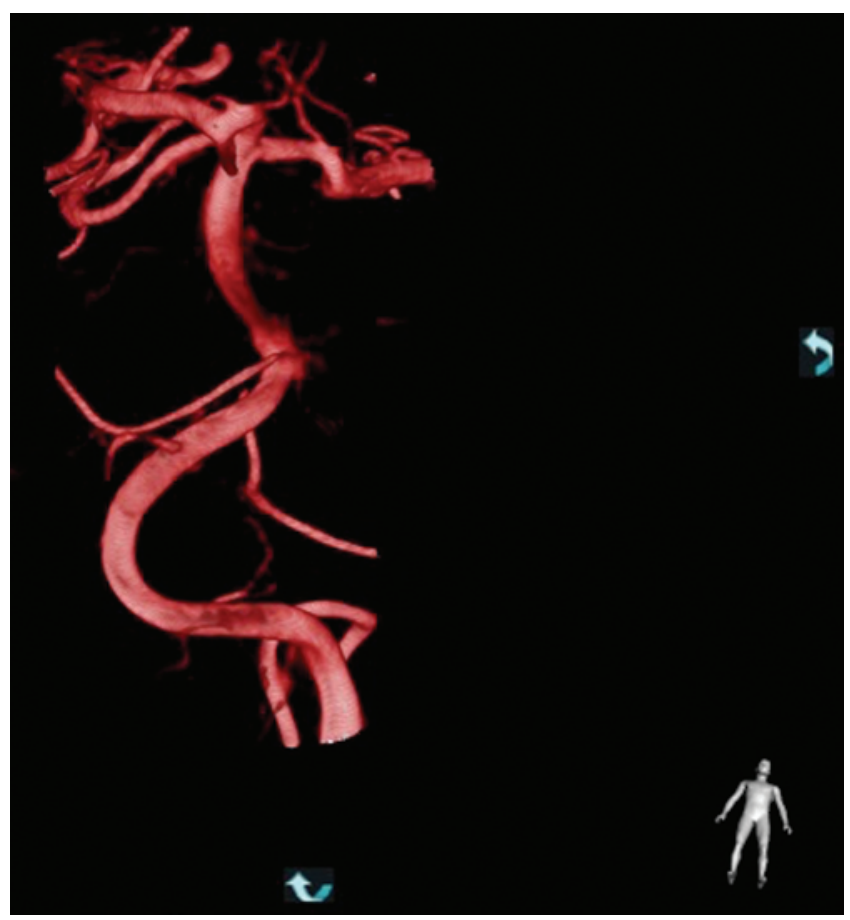

FIG. 6. Nine-month postembolization anteroposterior 3D cerebral angiogram reconstruction demonstrating no evidence of residual filling and a smooth contour of the basilar trunk at the level of the coiled aneurysm, with no evidence of thrombosis in the bilateral AICAs or basilar perforators. Figure is available in color online only. 
RIGHT PURE TONE AUDIOGRAM

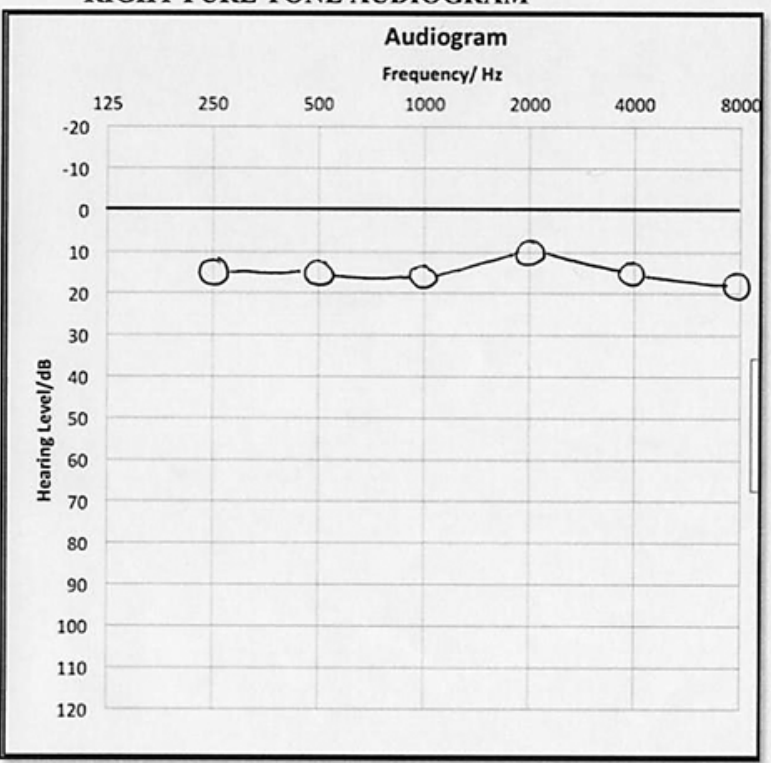

LEFT PURE TONE AUDIOGRAM

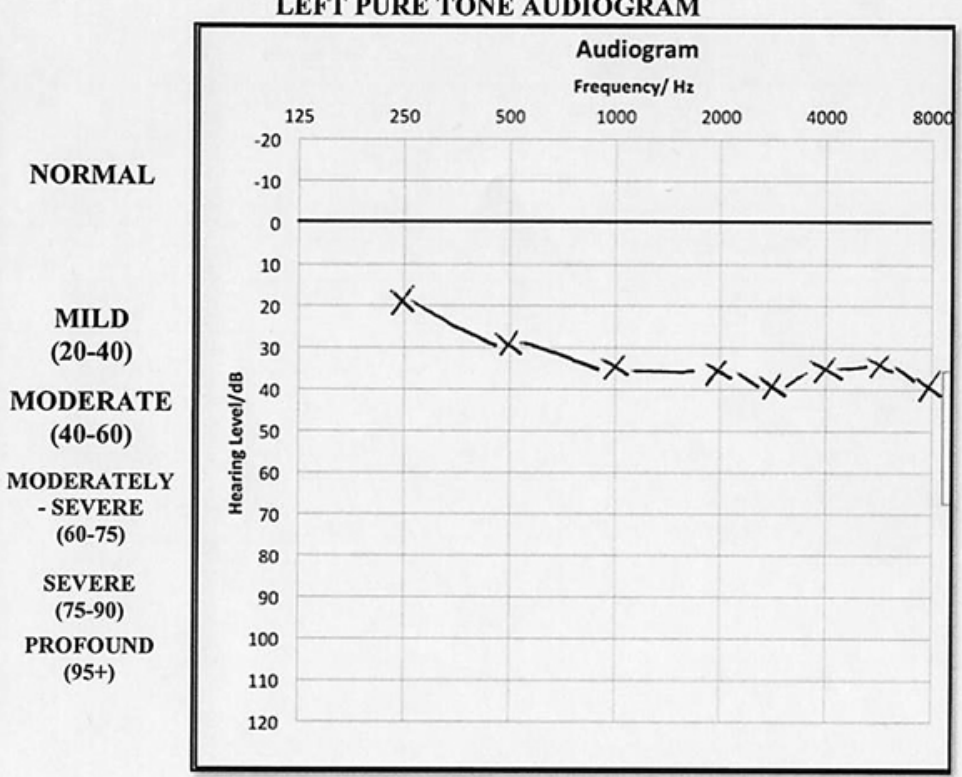

FIG. 7. Twenty-one month postembolization pure tone audiograms demonstrating normal hearing in the right ear (left) and mild loss to normal hearing in left ear (right).

high occlusion rates and low neurological complication rates. ${ }^{2}$ Flow diversion initially resulted in very poor results when used for posterior circulation aneurysms. ${ }^{15}$ However, recent data support the efficacy and safety of this device in very specific posterior circulation aneurysms, particularly those that have a small neck and those that do not involve long perforator-rich segments. ${ }^{1,9}$ Due to the relatively focal inflow and outflow of the aneurysm at the level of AICA in the present case, we decided to place a flow diverter with careful approximation of the AICA origins. This ensures that there is no space between the PED and the vessel, which is thought to create stasis and thrombosis. Because of the large size of the aneurysm, we also placed coils to promote thrombosis. It was felt that this would offer the patient the opportunity to have the most physiologically functional BA and theoretically the highest chance of long-term cure, given his young age. Although long-term data with PED are not yet available because of its relatively recent availability, aneurysm recurrence after complete obliteration is almost unheard of, and compared with the lifelong risk with palliative flow reversal or reduction, we thought flow diversion represented an advantage for our patient. We acknowledge that in these giant aneurysms, there can be growth despite angiographic obliteration due to vascularization of the wall itself, but we have not yet seen this in the 2-year follow-up of our patient.

There are also pediatric-specific concerns with this patient. On the one hand, treatment with flow diversion has unknown long-term outcome possibilities and the probable need for lifelong single-antiplatelet use. On the other hand, there is the potential for a true angiographic cure of the aneurysm, and to our knowledge, there are no cases of aneurysm recurrence after complete angiographic cure in flow-diversion treatment. Compared with the risk-benefit profile of flow reversal or other treatment options, we thought this was a favorable trade-off. With proximal oc- clusion and flow reversal with bypass, an aneurysm cure would be very unlikely, although the rate of growth and risk of rupture would likely be ameliorated. Similar to

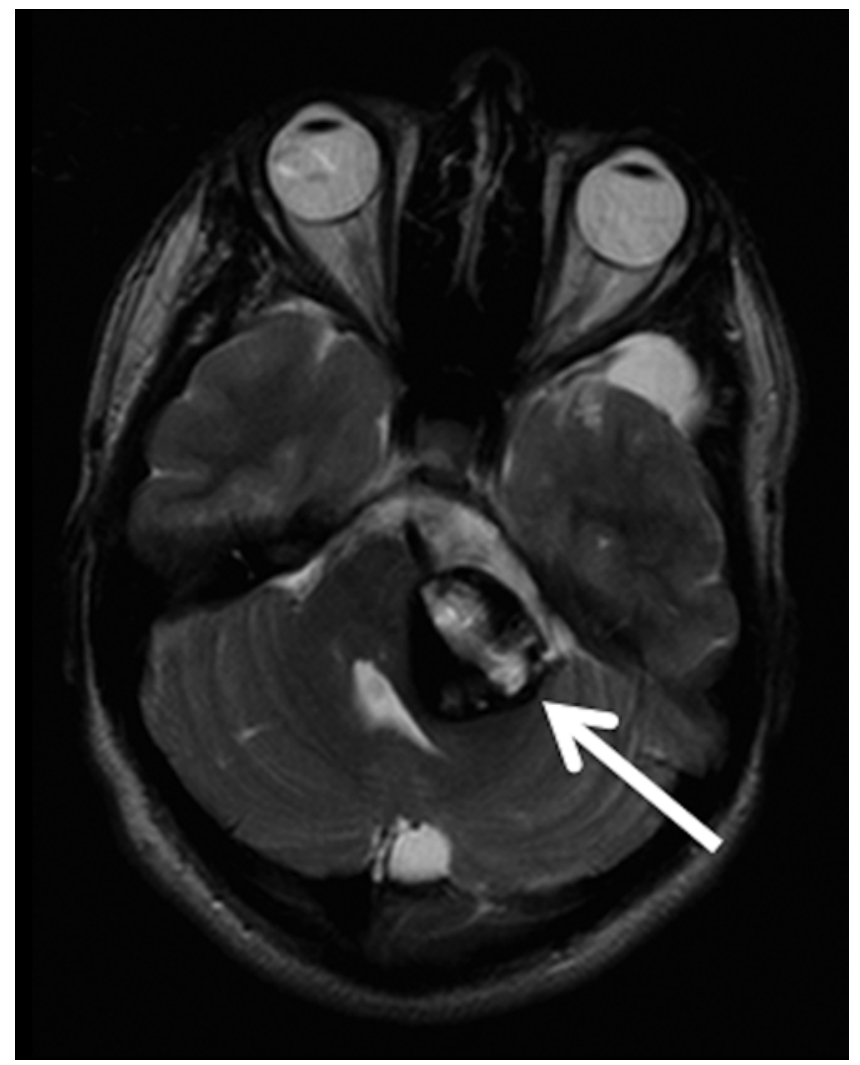

FIG. 8. Two-year postembolization axial MR image demonstrating retraction of the aneurysm size (solid arrow) and increased space around the brainstem and internal auditory canal bilaterally. 
flow diversion, the long-term outcomes of such flow-reversal procedures in a pediatric patient are unknown.

More impressive is that the patient in the present case had essential normalization of his hearing 2 years after intervention. This was likely a result of decreased mass effect on the brainstem and internal auditory canal. There is a body of literature that demonstrates restoration of hearing loss after chronic compression, specifically in patients who have undergone resection of cerebellopontine angle meningiomas and schwannomas, although this is very uncommon. ${ }^{3,6,7,10,12,14,17,19}$ Similar cases involving giant intracranial aneurysms have not been reported, to our knowledge. The resolution of compressive neuropathies in internal carotid artery aneurysms, however, after embolization with the PED is documented in the literature. ${ }^{18}$ To our knowledge, this is the first reported example of improvement in near-complete hearing loss following PED-based embolization of a giant BA aneurysm. Navarro et al..$^{13}$ reported on complex intracranial aneurysms in a small case series of pediatric patients treated with the PED in which they demonstrated complete resolution of the aneurysms without complication. This recent paradigm shift in the treatment of giant aneurysms in the pediatric population in selected cases has offered a solution that eliminates many of the risks associated with surgery, with the possibility of a curative outcome. We believe that the present case demonstrates potential utility of flow diversion even in a complex case with many factors that could be considered unfavorable for flow diversion (posterior circulation location, giant and partially thrombosed lesion, severe cranial nerve deficit, and marked brainstem compression). This case also underscores the potential for resolution even of posterior fossa compression symptoms in giant aneurysms.

\section{References}

1. Albuquerque FC, Park MS, Abla AA, Crowley RW, Ducruet AF, McDougall CG: A reappraisal of the Pipeline embolization device for the treatment of posterior circulation aneurysms. J Neurointerv Surg 7:641-645, 2015

2. Becske T, Kallmes DF, Saatci I, McDougall CG, Szikora I, Lanzino G, et al: Pipeline for uncoilable or failed aneurysms: results from a multicenter clinical trial. Radiology 267:858868,2013

3. Christiansen CB, Greisen O: Reversible hearing loss in tumours of the cerebello-pontine angle. J Laryngol Otol 89:1161-1164, 1975

4. Hanel RA, Spetzler RF: Surgical treatment of complex intracranial aneurysms. Neurosurgery 62 (6 Suppl 3):12891299, 2008

5. Kalani MYS, Zabramski JM, Nakaji P, Spetzler RF: Bypass and flow reduction for complex basilar and vertebrobasilar junction aneurysms. Neurosurgery 72:763-776, 2013

6. Katsuta T, Inoue T, Uda K, Masuda A: Hearing restoration from deafness after resection of a large cerebellopontine angle meningioma-case report. Neurol Med Chir (Tokyo) 41:352-355, 2001

7. Kileny PR, Edwards BM, Disher MJ, Telian SA: Hearing improvement after resection of cerebellopontine angle meningioma: case study of the preoperative role of transient evoked otoacoustic emissions. J Am Acad Audiol 9:251-256, 1998

8. Lawton MT, Daspit CP, Spetzler RF: Technical aspects and recent trends in the management of large and giant midbasilar artery aneurysms. Neurosurgery 41:513-521, 1997
9. Levitt MR, Park MS, Albuquerque FC, Moon K, Kalani MYS, McDougall CG: Posterior Inferior cerebellar artery patency after flow-diverting stent treatment. AJNR Am J Neuroradiol 37:487-489, 2016

10. Maurer PK, Okawara SH: Restoration of hearing after removal of cerebellopontine angle meningioma: diagnostic and therapeutic implications. Neurosurgery 22:573-575, 1988

11. Moon K, Albuquerque FC, Ducruet AF, Crowley RW, McDougall CG: Resolution of cranial neuropathies following treatment of intracranial aneurysms with the Pipeline Embolization Device. J Neurosurg 121:1085-1092, 2014

12. Nakamura M, Roser F, Dormiani M, Matthies C, Vorkapic P, Samii M: Facial and cochlear nerve function after surgery of cerebellopontine angle meningiomas. Neurosurgery 57:7790, 2005

13. Navarro R, Brown BL, Beier A, Ranalli N, Aldana P, Hanel RA: Flow diversion for complex intracranial aneurysms in young children. J Neurosurg Pediatr 15:276-281, 2015

14. Serbetçioglu MB, Sütay S, Ada E: Unusual regression of a sudden-onset sensorineural hearing loss in a patient with cerebellopontine angle pathology. J Laryngol Otol 115:733734,2001

15. Siddiqui AH, Abla AA, Kan P, Dumont TM, Jahshan S, Britz GW, et al: Panacea or problem: flow diverters in the treatment of symptomatic large or giant fusiform vertebrobasilar aneurysms. J Neurosurg 116:1258-1266, 2012

16. Steinberg GK, Drake CG, Peerless SJ: Deliberate basilar or vertebral artery occlusion in the treatment of intracranial aneurysms. Immediate results and long-term outcome in 201 patients. J Neurosurg 79:161-173, 1993

17. Stidham KR, Roberson JB Jr: Hearing improvement after middle fossa resection of vestibular schwannoma. Otol Neurotol 22:917-921, 2001

18. Szikora I, Marosfoi M, Salomváry B, Berentei Z, Gubucz I: Resolution of mass effect and compression symptoms following endoluminal flow diversion for the treatment of intracranial aneurysms. AJNR Am J Neuroradiol 34:935-939, 2013

19. Vellutini EA, Cruz OL, Velasco OP, Miniti A, Almeida GM: Reversible hearing loss from cerebellopontine angle tumors. Neurosurgery 28:310-313, 1991

20. Živković NZ, Marković M, Aleksić V, Jovanović MB: Giant vertebrobasilar fusiform aneurysm as a cerebellopontine angle mass. Srp Arh Celok Lek 143:731-733, 2015

\section{Disclosures}

Dr. Coon reports the following: Medtronic/Covidien, consultant and proctor; Stryker, consultant and proctor; MicroVention, consultant and proctor; and Sequent Medical, consultant and proctor. Dr. Coon's role as proctor and consultant is an acknowledged potential conflict of interest. Dr. Carlson, the senior author, conceived and designed the study, directed the treatment of this patient, and has no significant financial relationship with Medtronic.

\section{Author Contributions}

Conception and design: Carlson. Acquisition of data: Carlson, Mohammad. Analysis and interpretation of data: Carlson. Drafting the article: Mohammad. Critically revising the article: Carlson, Mohammad. Reviewed submitted version of manuscript: all authors.

\section{Correspondence}

Andrew P. Carlson, Department of Neurosurgery, University of New Mexico School of Medicine, 1 UNM, Albuquerque, NM 87131. email: andrewcarlson@salud.unm.edu. 